\title{
Succesful transplantation of human islets in recipients bearing a kidney graft
}

\author{
F. Bertuzzi ${ }^{1}$, F. Grohovaz ${ }^{2}$, P.Maffi ${ }^{3}$, A. Caumo ${ }^{4}$, L. Aldrighetti ${ }^{1}$, R. Nano ${ }^{1}$, P.Hengster ${ }^{5}$, G. Calori ${ }^{4}$, V.Di Carlo ${ }^{1}$, \\ E. Bonifacio $^{3}$, A.Secchi ${ }^{3}$ \\ ${ }^{1}$ Surgical Department ${ }^{2}$ CNR Cellular and Molecular Pharmacology Center and "B. Ceccarelli" Center, Neuroscience \\ Department ${ }^{3}$ Medicine Department ${ }^{4}$ Statistical Unit, S. Raffaele Scientific Institute, Milan, Italy \\ ${ }^{5}$ Department for Transplant Surgery, Innsbruck University Hospital, Innsbruck, Austria
}

\section{Abstract}

Aims/hypothesis. Islet transplantation is a minimally invasive approach to curing Type I (insulin-dependent) diabetes mellitus. Success has recently been reported in patients receiving solitary islet transplants but the outcome in patients receiving islets together with, or after, kidney transplants has been limited and unpredictable.

Methods. Here we report successful islet transplantation in a cohort of 15 patients with Type I diabetes who were followed for at least 1 year after islet transplantation, after having already received kidney allografts because of end-stage nephropathy.

Results. C-peptide after transplantation was higher than $0.17 \mathrm{nmol} / 1$ in all 15 recipients, reflecting the absence of primary non-function. Insulin requirement was reduced by over $50 \%$ in all but one patient, and insulin independence was achieved in $10(66 \%)$ recipients, five of whom now have stable, prolonged insulin independence, well controlled fasting glycae- mia, a substantial first-phase and normal secondphase response to glucose, normal insulin sensitivity (HOMA analyses) and $\mathrm{HbA}_{1 \mathrm{c}}$ of under $6.2 \%$ (33, $26,18,13$ and 12 months after transplantation respectively). Of importance for patient management, an assessment of fasting blood glucose and proinsulin values following overnight withdrawal of insulin administration one month after transplantation was a potent predictor of insulin independence, and could be used to decide patients who should have further islet preparations.

Conclusion/interpretation. These findings support the use of islet transplantation as a cure for Type I diabetes in patients with severe complications. [Diabetologia (2002) 45: 77-84]

Keywords Islet transplantation, kidney transplantation, primary non-function, insulin release, proinsulin release, intravenous glucose tolerance test, arginine test, insulin resistance.
Refinements in procedures of pancreas enzymatic digestion, and new immunosuppression strategies have allowed clinical trials of islet transplantation in patients with Type I (insulin-dependent) diabetes mellitus [1]. Until recently, the majority of transplants were done in patients who also receive kid-

Received: 23 April 2001 and in revised form: 30 July 2001

Corresponding author: F. Bertuzzi, Surgical Department, S. Raffaele Scientific Institute, via Olgettina 60, 20132 Milan, Italy, e-mail: bertuzzi.federico@hsr.it

Abbreviations: EI, Equivalent islets; $\left[\mathrm{Ca}^{2+}\right]_{\mathrm{i}}$ intracellular calcium concentration ney allografts [2]. Clinical results in these patients have not been satisfactory, with a 12 month survival of islet allografts (as defined by basal C-peptide $>0.17 \mathrm{nmol} / \mathrm{l}$ ) being achieved in less than $40 \%$ of recipients, and insulin independence in only $13 \%$ of recipients [2]. The number of recipients who become insulin independent after transplantation is low and so the procedure has also been considered successful when recipients maintained detectable serum C-peptide during follow-up [3-4] or $\mathrm{HbA}_{1 \mathrm{c}}$ was normalized [5]. Regardless of which outcome measure is used, around $30 \%$ of the cases reported in the International Registry of Transplantation (ITR) showed the absence of islet function af- 
ter transplantation, an event known as primary nonfunction [2].

More recently, highly successful islet transplantation using a new immunosuppression strategy has been achieved in 7 patients who underwent islet transplant alone [6]. Remarkable in comparison to previous trials in patients receiving islets after kidney or simultaneous islet and kidney transplants, all patients in the above Edmonton study halved their insulin requirement by 3 months after transplant. Insulin independence was eventually achieved in all patients, but with the transplant of a second islet preparation. This use of a second preparation in the Edmonton protocol, together with the variable engraftment and success seen in patients receiving islets after kidney transplants remain barriers to a wider application of islet transplantation to cure Type I diabetes. Particularly useful would be the availability of markers which could predict graft outcome relatively early so that transplant of less suitable islet preparations and second transplants could be avoided. In 1998 we recommenced our islet transplantation programme in patients who had received kidney allografts to characterise graft function during the first year after transplantation and to identify markers of islet quality and graft function which could indicate which islet preparations were most likely to function in vivo and predict graft function. Here we report the findings from the first 15 patients receiving islet allografts with at least 1 year follow-up. Fourteen of these patients reduced their insulin requirement by more than $50 \%$ and ten became insulin independent during follow-up.

\section{Subjects and methods}

Islet preparations. Islets were isolated from pancreas obtained from heart-beating, cadaveric multiorgan donors according to a modification of the automated method and purified by centrifugation on discontinuous gradient [7]. Islets were cultured at $22^{\circ} \mathrm{C}$ in a humidified atmosphere $\left(5 \% \mathrm{CO}_{2}\right)$, in M199 medium, supplemented with $10 \%$ FCS, $100 \mathrm{U} / \mathrm{ml}$ penicillin, $100 \mu \mathrm{g} /$ $\mathrm{ml}$ streptomycin sulfate and $2 \mathrm{mmol} / \mathrm{l}$ glutamine (Seromed Biochrom, Berlin, Germany).

Islets were initially tested for: sterility; endotoxin $(<0.25$ $\mathrm{EU} / \mathrm{ml}$ in all tested preparations; Chromogenic LAL test; Bio Whittaker, Walkersville, Md., USA) and mycoplasm (Mycoplasma detection kit; Boehringer Mannheim, Indianapolis, Ind., USA) content.

Preparations were considered adequate for transplantation if the following criteria were fulfilled: a number of equivalent islets (EI) over $5000 / \mathrm{kg}$ bw; a purity over $20 \%$ (morphometric determination of islet/total mass); and, finally, islet viability. This was assessed by the conventional trypan blue exclusion test ( $>90 \%$ ) and by videoimaging measurement of $\left[\mathrm{Ca}^{2+}\right]_{i}$, in fura-2 loaded islets as previously described [8]. Fluorescence images were collected by a low-light level CCD camera and fed into a home-made digital image processor where video frames were digitized and integrated in real time. At the beginning of each experiment the islets were rinsed with KRB and incubated for $20 \mathrm{~min}$ at $22^{\circ} \mathrm{C}$ with fura- 2 penta-acetoxymethylester $(2-5 \mu \mathrm{mol} / \mathrm{l})$ dissolved in KRB supplemented with $0.0125 \%$ Pluronic F-127 (Calbiochem, San Diego Calif., USA). At the end of the loading period the islets were gently rinsed in $\mathrm{KRH}$, allowed to adhere to polyornithine-coated coverslips and maintained under perifusion within the $10 \mu \mathrm{l}$ microchamber. Images were processed to convert fluorescence data in $\left[\mathrm{Ca}^{2+}\right]_{\mathrm{i}}$ images $(340 / 380 \mathrm{~nm}$ excitation wavelength ratio method). Mean values of the pixel intensity in the area of interest were calculated from the entire sequence of frames, thus providing a quantitative temporal analysis of $\left[\mathrm{Ca}^{2+}\right]_{\mathrm{i}}$ variations. In order to have a valid assessment of the basal $\left[\mathrm{Ca}^{2+}\right]_{i}$ values in the whole preparation, measurements were done in at least 30 individual islets from 3 distinct Petri dishes.

Islet transplantation into diabetic patients. Transplantation was performed between 24 and $72 \mathrm{~h}$ after isolation. The islet preparation was suspended in $100 \mathrm{ml}$ of Hanks' solution (Hanks Clinical Grade, Salf, Bergamo, Italy) containing 1000 U of heparin and $2 \%$ human albumin. Percutaneous trans-hepatic injection (under local anaesthesia) was performed according to the protocol approved by the Local Ethical Committee. A total of 23 islet preparations were transplanted into 15 HLA mismatched recipients affected by Type I diabetes mellitus (years of diabetes: median $=32$, range 12-48; see Table 1 ) and already under immunosuppression therapy for kidney transplantation. Altogether 7 of the 15 patients received a second islet preparation within 10 days from the first in order to reach the minimum number of about $6000 \mathrm{IE} / \mathrm{kg} \mathrm{b.w.} \mathrm{After} \mathrm{this}$ time window, no further islet preparations were transplanted in the recipients even when insulin independence had not been achieved, with the exception of patient 41 . This recipient received a second islet preparation (380, $000 \mathrm{EI}) 4$ months after the first transplant under a new treatment with anti-lymphocyte globulin (125 mg/day for 5 days). Only two complications were observed after the islet transplantation procedure: patient $33 \mathrm{had}$ an episode of hemothorax and patient $34 \mathrm{~b}$ a hemoperitoneum and both recovered spontaneously. Patient $34 \mathrm{~b}$ was transplanted at the Clinical University of Innsbruck. All recipients were negative for c-peptide (RIA, Diagnostic Products Corporation, LA, Calif., USA), with the exclusion of patients 30 (C-peptide $=0.39 \mathrm{nmol} / \mathrm{l}$, insulin requirement $34 \mathrm{U} /$ day) and 32 (0.26 nmol/1, insulin requirement 27U/day) where, however, C-peptide values were not responsive to arginine test (data not shown). All patients were already under immunosuppression therapy with steroids and cyclosporine for a previous kidney transplant. After islet transplantation, the therapy was changed as follows: anti-lymphocyte globulin $(125 \mathrm{mg} /$ day for 10 days; Thymoglobulin, Merieux, Lyon, France); cyclosporine $(7.5 \mathrm{mg} / \mathrm{kg} / \mathrm{day})$; mycophenolate mofetil (2 g/day); and methylprednisone (500 mg immediately before surgery, $0.25 \mathrm{mg} / \mathrm{kg}$ / day for two months after surgery, then lowered to $5 \mathrm{mg} / \mathrm{day}$ ). Patient $34 \mathrm{~b}$ received $2 \mathrm{mg} /$ day tacrolimus instead of cyclosporine. Anti-CD3 monoclonal antibodies ( $5 \mathrm{mg} /$ day, OKT3) was applied for 10 days for treatment of suspected rejections (rapid and stable increases of glycaemic values in absence of infectious episodes). Before transplantation, auto-antibodies to glutamic acid decarboxilylase (GAD) and tyrosine phosphatase-like protein (IA-2) were measured by radio-binding assay with in vitro translated ${ }^{35} \mathrm{~S}$-methionine labelled GAD65 or IA-2, as previously described [9].

During the first 10 days after the transplant, blood glucose was maintained between 4.4 and $7.0 \mathrm{mmol} / \mathrm{l}$ by continuous insulin infusion. Patients 25, 26, 28, 30, 32, 34, 35, 38, 40 and 41 also received a treatment based on pentoxyfillin $(1200 \mathrm{mg} /$ day), nicotinamide (1500 mg/day) [10] and metformin $(1000 \mathrm{mg} /$ day) to improve islet engraftment. During follow- 
Table 1. Clinical data of the recipients at the islet transplantation

\begin{tabular}{|c|c|c|c|c|c|c|c|c|c|}
\hline \multirow[t]{2}{*}{ Patient } & \multirow{2}{*}{$\begin{array}{l}\text { Age } \\
(\text { sex })\end{array}$} & \multirow{2}{*}{$\begin{array}{l}\text { Weight }(\mathrm{kg}) \\
\left(\mathrm{BMI}, \mathrm{kg} / \mathrm{m}^{2}\right)\end{array}$} & \multirow{2}{*}{$\begin{array}{l}\text { Years of } \\
\text { diabetes }\end{array}$} & \multirow{2}{*}{\multicolumn{2}{|c|}{$\begin{array}{l}\text { Autoantibodies } \\
\text { IA-2 } \\
\text { GAD }\end{array}$}} & \multicolumn{2}{|l|}{ HLA (A/B/DR) } & \multirow[t]{2}{*}{$\mathrm{EI} / \mathrm{Kg}$ b.w. } & \multirow{2}{*}{$\begin{array}{l}\text { Basal } \\
\mathrm{Ca}^{2+}(340 / 380)\end{array}$} \\
\hline & & & & & & recipient & donor & & \\
\hline 25 & $31(\mathrm{~F})$ & $52(23)$ & 12 & - & - & $1,3 / 37,44 / 2,7$ & $\begin{array}{l}2, \mathrm{X} / 7,18 / 15,11 \\
1,24 / 7,35 / 15,7\end{array}$ & 14,250 & $0.387 *$ \\
\hline 26 & $45(\mathrm{M})$ & $63(20)$ & 35 & - & - & $3,26 / 7,18 / 1,4$ & $\begin{array}{l}2,26 / 52,39 / 2,14 \\
31,33 / 58,27 / 1,11\end{array}$ & 11,430 & $0.308^{*}$ \\
\hline 28 & $47(\mathrm{~F})$ & $54(22)$ & 31 & + & - & $3,9 / 18,22 / 1,7$ & $\begin{array}{l}2,31 / 27,51 / 11 \\
2,30 / 18,35 / 11,13\end{array}$ & 11,668 & $0.558^{*}$ \\
\hline 29 & $41(\mathrm{M})$ & $64(22)$ & 22 & - & + & $3,29 / 44,62 / 4,11$ & $24, X / 35,61 / 11,16$ & 6,718 & 0.475 \\
\hline 30 & $48(\mathrm{~F})$ & $53(21)$ & 45 & + & + & $2,3 / 16, X / 1,4$ & $\begin{array}{l}2,24 / 51,44 / 1,11 \\
24 \mathrm{X} / 44,27 / 2,8\end{array}$ & 13,020 & $0.425^{*}$ \\
\hline 34 & $41(\mathrm{~F})$ & $52(21)$ & 23 & - & ++ & $3,23 / 39,35 / 3$ & $\begin{array}{l}2,24 / 52,13 / 15,7 \\
1,2 / 63,18 / 11,13\end{array}$ & 16,682 & nd \\
\hline $34 b$ & $51(\mathrm{M})$ & $60(23)$ & 19 & - & - & $2,96 / 8,27 / 17,52$ & $2,32 / 7,44 / 15,13$ & 7,650 & 0.315 \\
\hline 35 & $44(\mathrm{~F})$ & $55(21)$ & 38 & + & + & $1,2 / 44, \mathrm{Y} / 4,11$ & $3,25 / 35,55 / 1,15$ & 7,818 & 0.320 \\
\hline 38 & $42(\mathrm{~F})$ & $60(23)$ & $35 \mathrm{a}$ & - & + & $1,31 / 8,35 / 3,8$ & $\begin{array}{l}28,32 / 44,8 / 3,11 \\
3, X / 7,35 / 15,11\end{array}$ & 10,550 & $0.355^{*}$ \\
\hline 40 & $52(\mathrm{M})$ & $69(24)$ & 48 & - & - & $2,24 / 63,18 / 3,13$ & $\begin{array}{l}2,24 / 35, Y / 8,11 \\
1,2 / 8,35 / 3,14\end{array}$ & 9,870 & $0.311^{*}$ \\
\hline 41 & $47(\mathrm{M})^{\circ}$ & $84(28)$ & 29 & + & - & $3,24 / 18,44 / 3,4$ & $\begin{array}{l}1,11 / 52,55 / 7,14 \\
1,3 / 51,8 / 1,4\end{array}$ & 9,702 & 0.323 \\
\hline
\end{tabular}

Patients are numbered in a sequential series. Only patients after recommencement of the islet program in 1998 are included. Patients 36, 37, 39 received a solitary islet transplant and are not included in this study. Patient $34 \mathrm{~b}$ was transplanted and followed in Innsbruck. Patients 25, 26, 28, 30, 33, 34, 38, 40 and 41 received two distinct preparations; data marked by asterisks (*) represent the means of the values normalized according to the EI

Data analysis: beta-cell responsiveness. Beta-cell function was assessed by measuring the incremental (above basal) insulin responses during the IVGTT and the arginine test. During IVGTT, both the first-phase and second-phase insulin responses were measured. The first-phase (acute insulin response to glucose, AIRg) was calculated as the area of insulin excursion above basal values during the first $5 \mathrm{~min}$ of the test and the second-phase was similarly evaluated within the interval 5-60 min. The short-term insulin response to arginine (AIRa) was calculated as the area of insulin values above the basal during the first $10 \mathrm{~min}$ of test. Insulin resistance was measured using the homeostasis model assessment (HOMA [6, 12]). The HOMA insulin resistance index (HOMA-IR) was calculated as follows: [baseline insulin concentration $(\mu \mathrm{U} / \mathrm{ml}) \mathrm{x}$ baseline glucose concentration $(\mathrm{mmol} / \mathrm{l})] / 22.5$. Glucose tolerance was evaluated by estimating the glucose disappearance rate $(\mathrm{kG})$ during IVGTT. The $\mathrm{kG}$ was determined as the slope of the natural logarithm of glucose concentration over time obtained in the interval between 10 and 60 min of the IVGTT.

Statistical analyses. Survival analysis was used to study the relationship between the time at follow-up and the onset of insulin independence. The product-limit method was used to compute the survival distribution of time compared with insulin-independence as response. Results for measured parameters did 

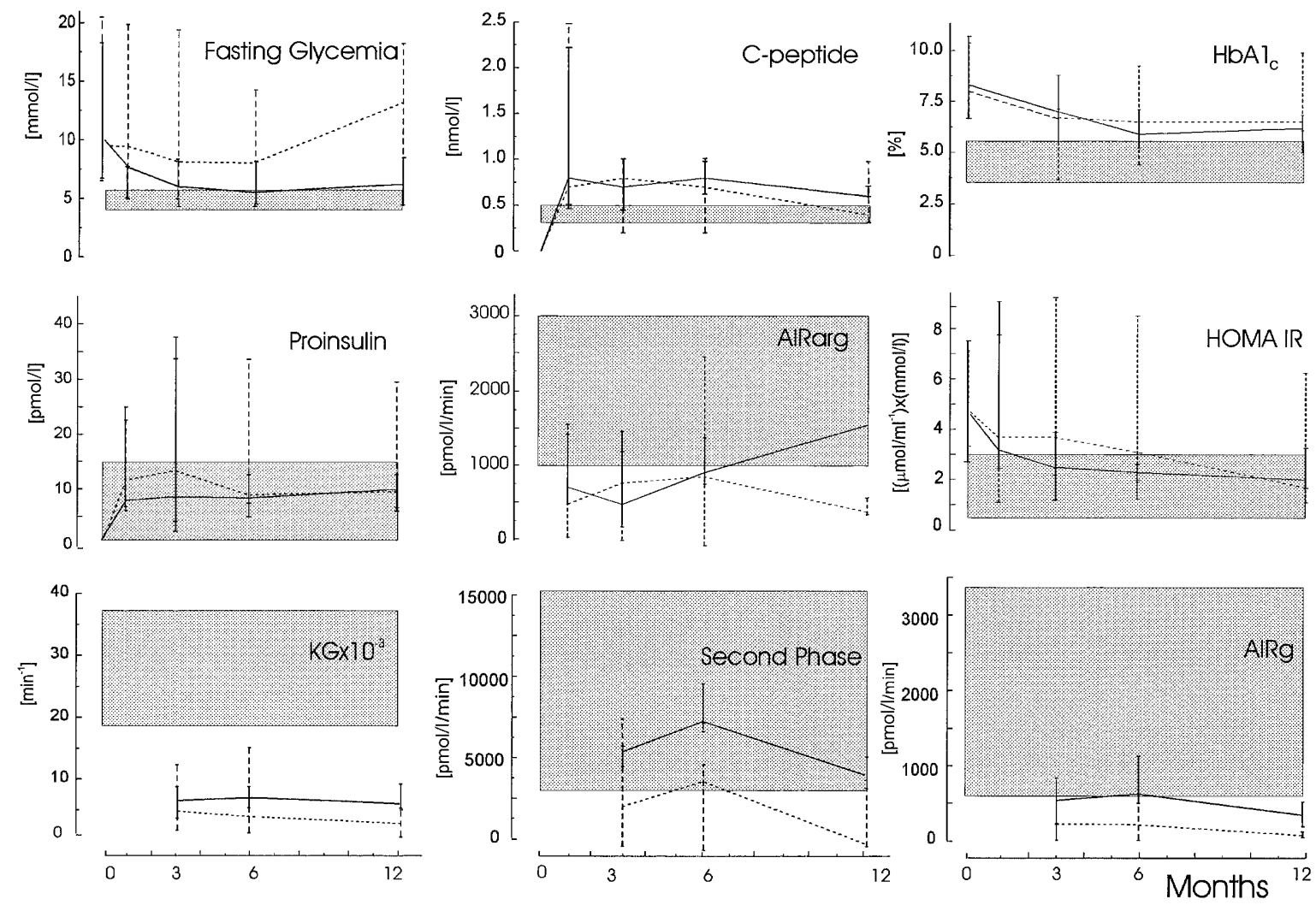

Fig. 1. In vivo parameters of graft function of insulin independent $(n=5)$ and insulin dependent $(n=10,---)$ patients 12 months after the transplant. Data are collected after overnight withdrawal of insulin administration during 12 months follow-up. Values represent median \pm minimum and maximum. Grey areas showed the range of control subjects parameters

not show a Gaussian distribution and are therefore expressed as median (minimum-maximum).

The Mann-Whitney or the Wilcoxon test was used to compare the data in different patient groups. Spearman rank correlation was performed between in vivo and in vitro parameters and subsequent insulin requirement. A $p$ value of less than 0.05 was considered to be statistically significant.

\section{Results}

Graft function: fasting assessment. Primary non-function was not observed and a viable islet mass could be maintained for at least 12 months. Fasting C-peptide concentrations were over $0.17 \mathrm{nmol} / 1$ during the entire follow-up (median value 0.8, range 0.4-2.4 nmol/l; Fig. 1) in all 15 patients with the exception of patient 38 , who at 1 year after transplantation had completely lost graft function through a presumed rejection episode. The probability of achieving insulin independence during follow-up was $59 \%$ by six months post-transplant. Ten patients (patients 25, 26,
$28,30,31,34,35,38,40$ and 41 ) became insulin independent between 1 and 11 months after transplant, and a further four (patients 27, 29, 32 and 34b) reduced their insulin requirement by more than $50 \%$. Five patients $(26,30,34,35$ and 41$)$ are still off insulin $34,27,19,14$ and 13 months after transplantation, respectively (see Fig. 2 for recipient insulin requirement profiles). The median insulin requirement 1 month after transplantation in the 15 patients was $44 \%$ of pre-transplant dose (from 0.82, range $0.45-1.11 \mathrm{U} / \mathrm{kg}$ b. w. pre-transplant to 0.36 , range $0-0.68 \mathrm{U} / \mathrm{kg}$ b.w. at 1 month $)$, and at 3 months was $29 \%(0.24 \mathrm{U} / \mathrm{kg}$ b.w., range $0-0.57 \mathrm{U} / \mathrm{kg} \mathrm{b.w.)}$, and all but one patient (33) had reduced their insulin requirement by more than $50 \%$ by 3 months post-transplant (Fig. 2). Although patients that reached insulin independence received more $\mathrm{EI} / \mathrm{kg}$ b.w. than insulin-dependent patients (11, $203 \pm 2901$ vs $7,973 \pm 2146)$, the difference was not significant, and no correlation was observed between the EI/kg b.w. of the recipients and their corresponding insulin requirement both at 6 and 12 months of follow-up. Five insulin independent patients $(25,28$, 31,38 and 40) required exogenous insulin therapy 1 , $1,2,3$ and 4 months respectively after insulin withdrawal. In three of these $(25,31$ and 38$)$, glycaemia increased acutely; in two, an anti-rejection treatment was able to completely (31) or partially (25) restore glucose profile. In patient 38 , however, this was ineffective. A slow and progressive increase in glycaemia was observed in two other patients ( 28 and 40$)$, leading to the introduction of low doses of insulin therapy. 

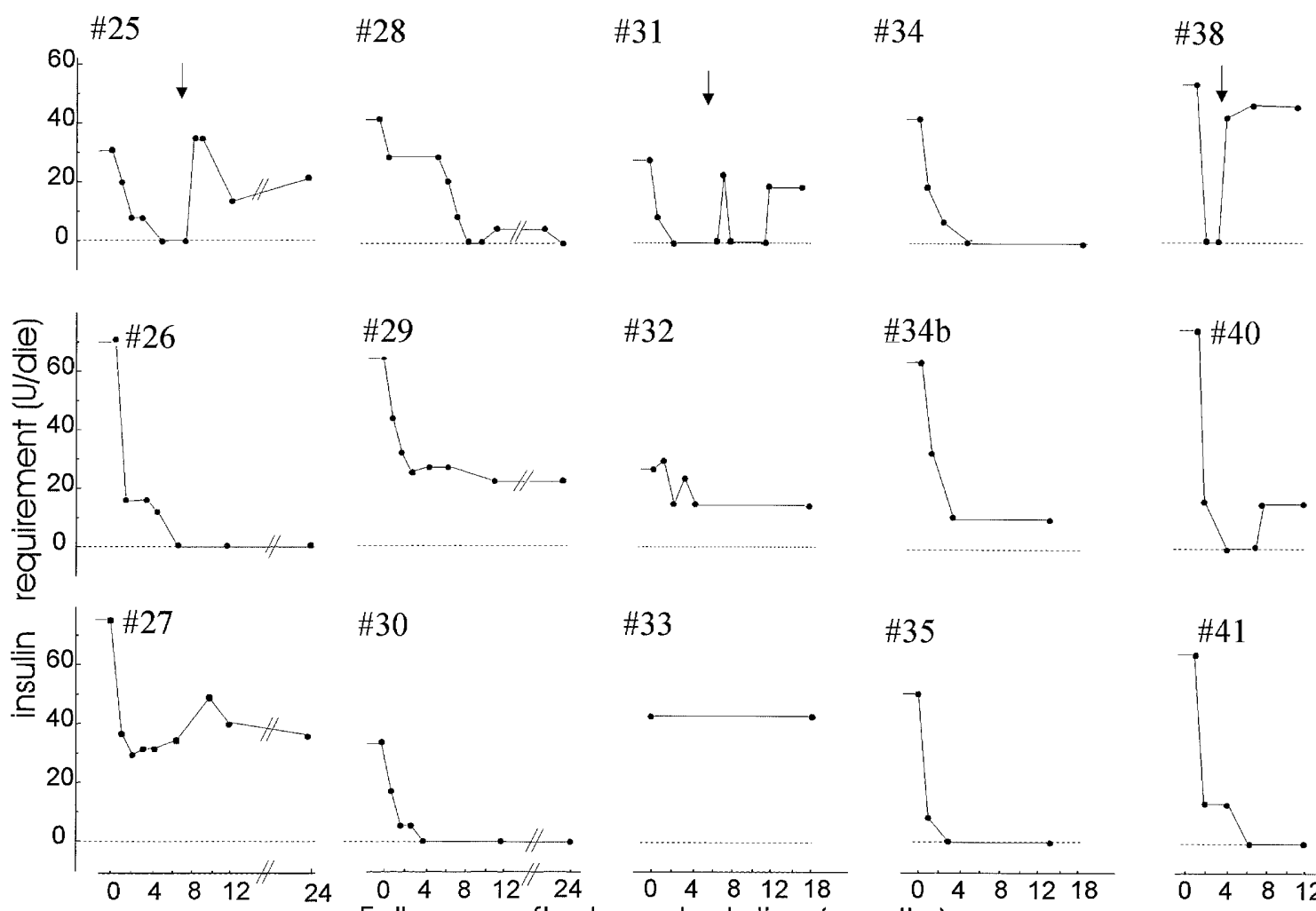

\#30
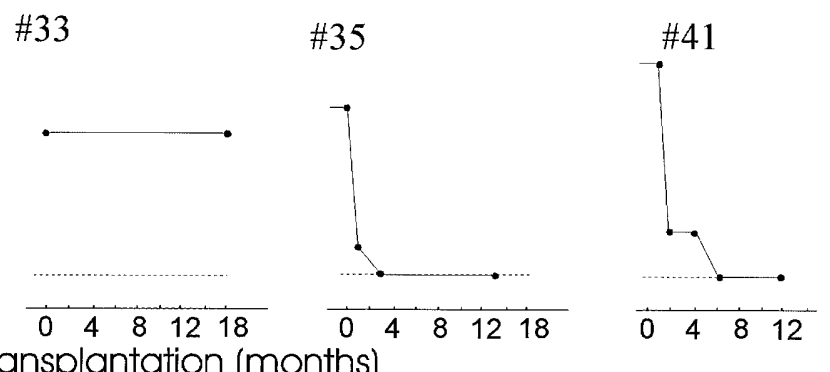

Fig. 2. Variations of insulin requirement after transplantation (time 0 ) in the 15 recipients. Capital letters identify the recipients of Table 1. Arrows (in patients 25, 31, 38) highlight rapid increases in insulin requirement. These episodes were interpreted as rejection episodes and treated accordingly

No difference in islet numbers was observed between patients who remained insulin independent (11656 \pm 3488 ) and those who lost their insulin independence $(10750 \pm 2502)$. Fasting glycaemia differed between patients who were off insulin 12 months after the transplantation and patients who were insulin dependent ( $p<0.05$, Fig. 1$)$.

Three months after transplantation, the mean $\mathrm{HbA}_{1 \mathrm{c}}$ had already significantly improved on pretransplant values, thus reflecting good metabolic control $(8.4,6.6-11.3 \%$ pre-transplant vs $6.8,3.9-8.5 \%$ at 3 months, $p<0.01$ ). Values remained less than $7.0 \% 1$ year after transplantation in 10 patients. Creatinine values were similar pretransplant (1.1, range $0.7-2.6 \mathrm{mg} / \mathrm{dl}$ ) and one year post-transplant (1.2, range $0.9-2.7 \mathrm{mg} / \mathrm{dl}$ ), one patient (28) showed a rise in creatinine from 1.3 to $1.8 \mathrm{mg} / \mathrm{ml}$ ).

Metabolic Indices. The metabolic indices obtained from the analysis of IVGTT and of arginine test allowed us to monitor the progression of beta-cell responsiveness, insulin resistance and glucose tolerance in the patients with transplants.
The parameters for assessing beta-cell response to glucose and arginine are reported in Figure 1. Insulin response to glucose showed a bi-phasic pattern with a first short-term response (AIRg) followed by a sustained second phase in most patients even though this was lower than those found in non-diabetic control subjects (median AIRg $=1773 \mathrm{pmol} / \mathrm{l} / \mathrm{min}$, median second phase $=7520 \mathrm{pmol} / 1 / \mathrm{min}$ ). The two phases were significantly correlated with each other at 3,6 and 12 months $(p<0.01)$. All five patients who remained insulin independent 1 year after transplantation had a moderately reduced AIRg and normal second-phase response (Fig. 2). AIRg and second phase at 6 and 12 months were significantly different between patients off insulin, and those who were insulin dependent $(p<0.05)$.

The second phase at 3,6 and 12 months, and AIRg at 6 and 12 months were inversely correlated with the corresponding insulin requirement $(p<0.05)$. In addition, both the mean values of AIRg and secondphase insulin response at 3 and 6 months were negatively correlated with the corresponding fasting proinsulin ( $p \leq 0.01)$, suggesting that an increase of proinsulin concentrations is associated with a decline in graft ability to respond to a glucose challenge. AIRg values did not significantly correlate with the corresponding AIRa.

The HOMA-IR index was used to assess insulin resistance based on the fasting glucose and insulin concentrations measured before arginine test and IVGTT. HOMA-IR decreased 3 to 6 months after 
transplantation (Fig. 2). Improved HOMA-IR indices were particularly evident already at 6 months followup in those who were insulin independent (see Fig. 2), being similar to those of control subjects. The mean values of HOMA at 3 and 6 months were negatively correlated with both the AIRg and the second phase $(p<0.05)$, suggesting that a reduction of insulin resistance is associated with the graft ability to respond to a glucose challenge

Values of glucose tolerance $(\mathrm{kG})$ measured from IVGTT glucose data slightly decreased during follow-up, although not in a statistically significant manner and never reached the control group.

In vitro and in vivo predictors of graft function. In order to identify potential markers of islet quality which could serve as additional transplant selection criteria, a statistical analysis was performed between the in vitro islet measurements (IE, $\left[\mathrm{Ca}^{2+}\right]_{i}$, purity) and the percentage insulin requirement within the first 6-month follow-up in all patients. A correlation was observed between islet basal $\left[\mathrm{Ca}^{2+}\right]_{\mathrm{i}}$ and the insulin requirement early after transplantation (at 1,3 and 6 month follow-up, $p<0.05$ ).

A similar analysis was done between in vivo parameters of graft function and 12 months insulin requirement. Insulin requirement significantly correlated with fasting glycaemia and proinsulin values after overnight insulin withdrawal at 1 month after the transplantation. The Mann-Whitney analyses confirmed a statistically difference between fasting glycaemic values of patient still off insulin and the others $(p=0.05)$.

\section{Discussion}

Islet transplantation represents an attractive alternative therapy to conventional insulin treatment or vascularized whole pancreas transplantation $[1,13]$. Success has recently been reported in Edmonton in patients receiving solitary islet transplants but outcome in patients receiving islets together with, or after, kidney transplants, representing the majority of islet transplanted cases, has been limited and unpredictable [2]. Several factors could determine the success of the clinical outcome, starting from the quality of the preparations to be transplanted, up to islet engraftment or immunological responses in the recipient or both $[3,4,13-15]$. In this work, we report a comprehensive longitudinal study of the metabolic profile of Type I diabetic recipients of pancreatic islet transplant who had already undergone kidney transplantation because of end-stage nephropathy. Of note, compared to the clinical profiles reported in the ITR, we found that C-peptide values in our recipients were always over $0.17 \mathrm{nmol} / \mathrm{l}$, reflecting the $\mathrm{ab}$ sence of primary non-function and suggesting that a refinement of the procedures for preparing and screening islet preparations can avoid early graft failure; and also insulin independence, that was reached in only about $13 \%$ of ITR recipients (2) and in about $30 \%$ of our previous patients [16] was achieved in $60 \%$ of cases. Impressively, five patients in this series now have stable prolonged insulin dependency more than 1 year after transplantation with well controlled glycaemia, a substantial first phase and normal second phase response to glucose, normal insulin sensitivity and $\mathrm{HbA}_{1 \mathrm{c}}$ below $7.0 \%$.

When comparing the outcome in our cohort with that in the Edmonton cohort, it is notable that the performance was similar in the early post-transplant phase with a reduction in the insulin requirement by around $50 \%$ after 1 month (the median time between the two islet infusions in Edmonton study) in both cohorts. Thereafter, $86 \%$ of patients in the Edmonton cohort developed stable insulin independence [17], whereas $66 \%$ of our cohort became insulin independent and in only half of these was the insulin independent period stable and prolonged 1 year after transplantation. On the one hand, our data show that stable insulin independence can be achieved in the absence of transplanting subsequent islet preparations and with relatively few islets. On the other hand, suggest that there are patients who would become insulin independent if they received a further islet preparation. The use of prolonged induction protocols such as in the Edmonton study means the identification of early predictors of graft function becomes an important issue. As reported for pancreas transplantation [18], basal fasting glucose concentrations after overnight withdrawal of insulin were predictors of outcome, being markedly increased one month after transplantation only in recipients who did not become insulin independent. Also fasting proinsulin values after overnight withdrawal of insulin were found to be increased in our patients with a poor functioning graft, in line with that reported in patients with newly diagnosed Type II diabetes [19], in hemipancreatectomized patients[20] and in a case report of islet transplantation in Type I diabetic patient [21]. In view of these data, the transplantation of further islets should be considered already 1 month after transplantation in patients who have higher fasting blood glycaemia and proinsulinemia or both.

Interestingly, C-peptide values, widely considered representative of graft function [2], did not reveal any relationship with the final outcome of transplantation, and assessment of peripheral insulin was also inadequate to follow graft function. In our study, neither served as a useful marker to identify patients who would benefit from additional islets. AIRg is often considered to be representative of graft secretory function [22, 23], and our data showed that AIRg values measured during the follow-up do correlate with corresponding insulin requirement. AIRa did not 
show a similar correlation. This was expected because discrepancies between responses to glucose and arginine are reported in subjects with glucose intolerance or diabetes [23].

In addition to responses to stimuli, we measured the effect of islet transplantation on insulin resistance. HOMA was used because the minimal model is largely inadequate to assess insulin sensitivity in recipients of islet allograft because of their low insulin response to glucose [5]. All patients who achieved insulin independence had normal HOMA values, suggesting that a proper metabolic control favours a decrease in insulin resistance which, in turn, plays an important role in reducing insulin requirement $[6,24]$. Therefore, in the recipients who did not reach insulin independence, the progressive decrease of graft function might be due to impaired islet secretory reserve as well as increased metabolic demand secondary to insulin resistance. The consequence is progressive islet exhaustion with ensuing deterioration of graft. This is also supported by the observation of an increase in proinsulin release in some of our patients during periods of islet function but insulin dependency.

Finally, it is interesting to contrast the method of islet transplantation used with this cohort with that in the Edmonton study. Innovative aspects of the Edmonton study include the infusion of islets without a prolonged culture period, the transplant of a second islet preparation in all recipients, the transplant of a total of at least $11000 \mathrm{EI} / \mathrm{kg}$ in each patient, transplantation into patients with Type I diabetes who had not received other organ grafts, and the use of a new steroid and cyclosporin-A-free therapy. While all these modifications could contribute to the improved outcome, it is noteworthy that in our cohort stable insulin independence was achieved using single islet preparations cultured for at least $24 \mathrm{~h}$ and containing less than $8000 \mathrm{EI} / \mathrm{kg}$, and there was no relationship between insulin independence and islet number or the number of preparations received. In our study, we used for the first time basal $\left[\mathrm{Ca}^{2 \pm}\right]_{\mathrm{i}}$ assessment as parameter of islet viability used for islet selection for the transplant. It has long been known that sustained variation of $\left[\mathrm{Ca}^{2+}\right]_{\mathrm{i}}$ is an early sign of altered cellular function [25-28] that can eventually evolve into the cell death [29]. At this stage we can only speculate about the role of these $\left[\mathrm{Ca}^{2+}\right]_{i}$ alterations on the grafted cells. The toxic effect of $\mathrm{Ca}^{2+}$ can be rapid (necrosis) when a massive increase occurs, but death can be delayed for days (apoptosis) upon moderate displacement from the physiological concentrations [29]. Apoptosis might thus be triggered during the period that precedes transplantation and escape conventional in vitro criteria: cells committed to apoptosis could seem in a healthy state, and cellular functions, including regulated secretion, could be preserved [29]. Thus further studies are required to clarify if measurement of basal $\left[\mathrm{Ca}^{2+}\right]_{\mathrm{i}}$, could be a useful marker of islet function which could replace other parameters of viability for the selection of islet preparations for the transplant.

In conclusion, we demonstrate successful islet transplantation in patients with Type I diabetes with kidney allografts, success being defined as an absence of primary non-function in all patients, a marked reduction in insulin requirement in all but one patient, insulin independence in $66 \%$ of recipients which was stable and prolonged 1 year after transplantation in five patients, and decreased insulin resistance in patients who became insulin independent. We found that function one month post-transplant can be used to identify patients who do not need transplantation of additional islets in order to achieve insulin independence. These findings are useful in view of the recent success obtained in solitary islet transplantation and support the use of islet transplantation as a cure for Type I diabetes in patients afflicted with severe complications.

Acknowledgements. We wish to thank M. Santopinto, P. Magistretti, P. V. Chuong, A. Caputo for excellent technical assistance. We thank Prof. G. Pozza, for continuous supporting the islet programme; L. Luzi for a critical reading of the manuscript and with G. Fragasso for the contribution of the control data. We also thank A. M. Davalli and D. Guiducci for their hard work in following our recipients and B. Clissi for her contribution in human islet preparations. We gratefully acknowledge the financial support of CNR Target projects on "Biotechnology" (F. Grohovaz; V. Di Carlo), Telethon (E.443), JDF (I 2000-780) and the Armenise-Harvard Foundation.

\section{References}

1. Ricordi C (1992) Pancreatic islet cell transplantation. R. G. Landes, Austin

2. Brendel MD, Hering BJ, Schultz AO, Bretzel RG (1999) International Islet Transplant Registry. Newsletter 8, Giessen, Germany

3. Roep BO, Stobbe I, Duinkerken G et al. (1999) Auto-and alloimmune reactivity to human islet allografts tranplanted into type 1 diabetic patients. Diabetes 48: 484-490

4. Jaeger C, Brendel MD, Hering JB, Eckhard M, Bretzel RG (1997) Progressive islet graft failure occurs significantly earlier in autoantibody-positive than in autoantibody-negative IDDM recipients of intrahepatic islet allografts. Diabetes 46: 1907-1910

5. Alejandro R, Lehmann R, Ricordi C et al. (1997) Long term function ( 6 years) of islet allografts in type 1 diabetes. Diabetes 46: 1983-1989

6. Shapiro AMJ, Lakey JRT, Ryan EA et al. (2000) Islet transplantation in seven patients with type 1 diabetes mellitus using a glucorticoid-free immunosuppressive regimen. N Engl J Med 343: 230-238

7. Socci C, Falqui L, Davalli AM et al. (1991) Fresh human islet transplantation to replace pancreatic endocrine function in type I diabetic patients (a report of six cases). Acta Diabetol 28: 151-157

8. Bertuzzi F, Davalli AM, Nano R et al. (1999) Mechanisms of coordination of $\mathrm{Ca} 2$ + signals in pancreatic islet cells in response to glucose stimulation. Diabetes 48: 1971-1978 
9. Verge CF, Stenger D, Bonifacio E et al. (1998) Combined use of autoantibodies (IA-2 autoantibody, GAD autoantibody, insulin autoantibody, cytoplasmic islet cell antibodies) in type 1 diabetes: Combinatorial Islet Autoantibody Workshop. Diabetes 47: 1857-1866

10. Bretzel RG, Brandhorst D, Brandhorst H et al. (1999) Improved survival of intraportal pancreatic islet cell allografts in patients with type- 1 diabetes mellitus by refined peritransplant management. J Mol Med 77: 140-143

11. Davalli AM, Ricordi C, Socci C et al .(1991) Abnormal sensitivity to glucose of human islets cultured in a high glucose medium: partial reversibility after an additional culture in a normal glucose medium. J Clin Endocrinol Metab 72: 202-208

12. Levy JC, Matthews DR, Hermans MP (1998) Correct homeostasis model assessment (HOMA) evaluation uses the computer program. Diabetes Care 21: 2191-2192

13. Berney T, Ricordi C (1999) Islet transplantation. Cell Transplant 8: 461-464

14. Kaufman DB, Platt JL, Rabe FL, Dunn DL, Bach FH, Sutherland DER (1990) Differential roles of Mac- $1^{+}$cells, and $\mathrm{CD}^{+}$and $\mathrm{CD}^{+} \mathrm{T}$ lymphocytes in primary non-function and classic rejection of islet allografts. J Exp Med 172: 291-302

15. Weir GC, Bonner-Weir S (1997) Scientific and political impediment to successful islet transplantation. Diabetes 46: 1247-1256

16. Secchi A, Socci C, Maffi P et al. (1997) Islet transplantation in IDDM patients. Diabetologia 40: 225-231

17. Ryan EA, Lakey JRT, Rajotte RV et al. (2001) Clinical outcomes and insulin secretion after islet transplantation with the Edmonton protocol. Diabetes 50: 710-719

18. Battezzati A, Benedini S, Caldara R et al. (2000) Prediction of long-term metabolic success of the pancreatic graft function. Transplantation 71: 1560-1565

19. Mykkanen L, Zaccaro DJ, Hales CN, Festa A, Haffner SM (1999) The relation of proinsulin and insulin to insulin sensitivity and acute insulin response in subjects with newly di- agnosed Type II diabetes: the Insulin Resistance Study. Diabetologia 42: 1060-1066

20. Seaquist ER, Kahn SE, Clark PM, Hales N, Porte D, Robertson RP (1996) Hyperproinsulinemia is associated with increased $\beta$ cell demand after hemipancreatectomy in humans. J Clin Invest 97: 455-460

21. Davalli AM, Maffi P, Socci C et al. (2000)Insights from a successful case of intrahepatic islet transplantation into a type 1 diabetic patient. J Clin Endocrinol Metab 85: 3847-3852

22. Christiansen E, Tibell A, Volund A et al. (1994) Insulin secretion, insulin action and non-insulin-dependent glucose uptake in pancreas transplant recipients. J Clin Endocrinol Metab 79: 1561-1569

23. Rakotoambinina B, Timsit J, Deschamps I et al. (1997) Insulin responses to intravenous glucose, intravenous arginine and a hyperglycaemic clamp in ICA-positive subjects with different degrees of glucose tolerance. Diabetes Metab 23: 43-50

24. Luzi L, Hering BJ, Socci C et al.(1996) Metabolic effects of successful intraportal islet transplantation in IDDM. J Clin Invest 97: 2611-2618

25. Murata M, Monden M, Umeshita K et al. (1994) Role of intracellular calcium in superoxide-induced hepatocyte injury. Hepatology 19: 1223-1228

26. Nedergaard M (1995) Intracellular Ca2 + transients evoked by lactic acid in cultured mammalian neurons. Am J Physiol 268: R506-R513

27. Dziki AJ, Batzri S, Harmon JW, Molloy M (1995) Cellular hypercalcemia is an early event in deoxycholate injury of rabbit gastric mucosal cells. Am J Physiol 269: G287-G296

28. Ferger D, Krieglstein J (1996) Determination of intracellular $\mathrm{Ca} 2+$ concentration can be a useful tool to predict neuronal damage and neuroprotective properties of drug. Brain Res 732: 87-94

29. Majno G, Joris I (1995) Apoptosis, oncosis, and necrosis. An overview of cell death. Am J Pathol 146: 3-15 